\title{
Significado tectônico de lineamentos de drenagem no sudoeste da ilha do Marajó
}

\author{
Luiz Rogério Mantelli ${ }^{1}$ \& Dilce de Fátima Rossetti ${ }^{1}$
}

\begin{abstract}
Resumo A análise de propriedades da drenagem tem relevância em estudos geológicos, podendo revelar informações importantes relativas ao contexto tectônico. Este tipo de estudo é particularmente relevante em áreas de altitudes muito baixas, como é o caso da ilha do Marajó, onde características ligadas ao relevo são inexpressivas. O trabalho teve por objetivo principal a caracterização e análise das bacias hidrográficas no sudoeste da ilha do Marajó, visando o reconhecimento de parâmetros geomorfológicos que permitam discutir a possível influência de reativações tectônicas na região. Os resultados, obtidos por meio da análise de produtos de sensoriamento remoto, revelaram uma série de feições relevantes a este tipo de estudo, como abundância de canais retilíneos comumente conectados em ângulos elevados, que chegam a $90^{\circ}$; padrão sub-dendrítico com influência de treliça, angular e, menos comumente, retangular; e presença de anomalias de drenagem como rápida mudança de padrão dentro da mesma bacia de drenagem, ocorrência de meandramento localizado em canal dominantemente retilíneo, e súbito alargamento de canais. Adicionalmente, o predomínio de lineamentos de drenagem com direções NE-SW, NW-SE e, subordinadamente E-W, são concordantes com orientações principais de falhas tectônicas reconhecidas na área de estudo e em várias outras áreas da região Amazônica, o que suporta controle tectônico no desenvolvimento do sistema de drenagem da área de estudo. A reativação de falhas tectônicas pré-existentes durante o Pleistoceno tardio e Holoceno representa um importante fator na criação de espaço para acomodação de sedimentos desta idade na ilha do Marajó.
\end{abstract}

Palavras-chave: sensoriamento remoto, lineamentos morfoestruturais, tectônica, Quaternário, ilha do Marajó.

\begin{abstract}
Tectonic significance of drainage lineaments in southwestern Marajó island. The analysis of drainage properties is of great significance in geological studies, having the possibility to provide important information concerning to the tectonic context. This type of study is particularly significant in areas of low topography, such as Marajó Island, where features linked to relief are not relevant. This work had the main goal of furnishing an analysis of the hydrographic basins in southwestern Marajó Island, aiming the recognition of geomorphologic parameters to allow a discussion on the possible influence of tectonic reactivations in this region. The results, derived from the analysis of remote sensing data, revealed a series of features that are relevant in this type of study, such as straight channels commonly connected at high angles that reach up to $90^{\circ}$; dominance of sub-dendritic drainage pattern with trellis influence, as well as angular and, less commonly, rectangular patterns; drainage anomalies such as rapid changes in patterns within a same basin, local meandering in dominantly straight channels, and subtle channel enlargement. The prevalence of drainage lineaments displaying NE-SW, NW-SE, and subordinately E-W directions conform to main orientations of tectonic faults from both the study area and many other areas in the Amazon region, which is consistent with a tectonic control on the development of the drainage system of the study area. The reactivation of pre-existent tectonic faults during the late Pleistocene and Holocene represents an important factor for the creation of new space to accommodate sediments of this age in Marajó Island.
\end{abstract}

Keywords: remote sensing, morphostructural lineaments, tectonics, Quaternary, Marajó Island.

INTRODUÇÃO A ilha do Marajó tem sido alvo de crescente investigação no tocante à sedimentação quaternária tardia a holocênica, visando reconstituir sua história paleambiental (Rossetti \& Valeriano 2007, Rossetti et al. 2007, 2008a,b). De particular interesse em estudos desse gênero é o reconhecimento de reativações tectônicas como mecanismo primordial à geração de espaço para acomodação de depósitos dessa idade (Rossetti et al. 2008a). Nesta área de relevo extremamente baixo, a tectônica torna-se um fator de fundamental importância para explicar significativas espessuras (i.e., várias deze- nas de metros) de sedimentos pleistocênicos tardios a holocênicos, como documentadas no leste da ilha (Bemerguy 1981, Porsani 1981, Rossetti et al. 2007a). Este contexto geológico é condizente com numerosos estudos que mostram que atividades tectônicas foram importantes durante o Quaternário em muitas outras áreas da região Amazônica (Costa et al. 1996, 1997, 2001, Costa \& Hasui 1997, Bezerra 2003, Silva et al. 2005, AlmeidaFilho \& Miranda 2007).

As principais evidências de movimentações tectônicas quaternárias na Amazônia são baseadas em dados 
geomorfológicos. O uso de produtos de sensoriamento remoto e, em especial, de dados SRTM (Shuttle Radar Topography Mission), tem sido de grande relevância em estudos desse gênero, tornando-se cada vez mais freqüente nessa região (p.e., Rozo et al. 1982, Souza Filho 2000; Souza Filho \& El Robrini 2000, Paradella et al. 2000a,b, 2001, Martins et al. 2005, Souza Filho \& Paradella 2003, Silva et al. 2007, Rossetti \& Valeriano 2007, Almeida-Filho \& Miranda 2007, Rossetti et al. 2007, 2008a,b). A ampla distribuição geográfica, densa cobertura vegetal natural, dificuldade de acesso, e carência de estudos sistemáticos, fazem com que a Região Amazônica seja favorável à aplicação de produtos de sensoriamento remoto como ferramenta de aquisição rápida de informações nos diversos temas da ciência.

Dentre os parâmetros geomorfológicos, a caracterização da drenagem constitui-se em elemento de grande significado em estudos geológicos, podendo revelar importantes informações relativas ao contexto tectônico. Estudos anteriores mostram que canais fluviais da Amazônia, tanto atuais, quanto passados, têm controle estrutural (RADAM 1974, Bemerguy 1997, 1981, Bemerguy et al. 2002, Rossetti et al. 2007, 2008a,b). Particularmente, em áreas de altitudes muito baixas, como é o caso da ilha do Marajó, a análise de drenagem torna-se de especial interesse na caracterização geológica do terreno. Estudo recente apresentou resultados deste tipo de investigação no leste da ilha do Marajó (Rossetti et al. 2008a), porém inexistem trabalhos do gênero para o restante da ilha.

A utilização da rede drenagem como ferramenta de análise geomorfológica requer mapas de boa resolução. Para o caso da ilha do Marajó, uma avaliação preliminar da base cartográfica de drenagem digital do IBGE/SIPAM disponível para a área de estudo na escala 1:100.000 mostrou a necessidade de melhoramento, já que inúmeras drenagens visualizadas em dados SRTM não estão inseridas neste mapa. Isto pode ser feito de forma manual, o que requer tempo, ou automática. Existem várias técnicas de extração de drenagem automática a partir de modelos digitais de elevação (p.e., Deffontaines \& Chorowicz 1991, Martz \& Garbrecht 1992, Curkendall et al. 2003, Jordan et al. 2005). Resultados de extração automática de drenagem mostram coincidência de até $98 \%$ quando comparada com dados de extração manual (Jenson \& Domingue 1988), mesmo em áreas com relevos rebaixados (Martins et al. 2005). Entretanto, a extração automática de drenagens em áreas de relevos extremamente baixos necessita ainda ser testada.

Este trabalho objetiva fornecer um mapa do sistema de drenagem atual para o sudoeste da ilha do Marajó, de forma a disponibilizar dados que possibilitem caracterizar e analisar as bacias hidrográficas visando verificar se existe controle tectônico no desenvolvimento da drenagem nesta região, como previamente registrado para a porção oriental da ilha. Dado o crescente interesse na extração automática de drenagem em áreas amazônicas, o presente trabalho tem, ainda, como objetivo analisar a eficiência da extração de drenagem em áreas de relevo extremamente baixo utilizando-se dados SRTM, de forma a testar sua aplicação em outras áreas amazônicas com características similares.

FISIOGRAFIA E GEOLOGIA A ilha do Marajó, com 250.000 habitantes, está situada no Estado do Pará, a aproximadamente $90 \mathrm{~km}$ da cidade de Belém, onde cobre uma área de $50.000 \mathrm{~km}^{2}$. Esta ilha é limitada pelo rio Amazonas a norte, rios Pará e Tocantins a sul, e pelo Oceano Atlântico a leste. O município de Breves, onde a área de estudo está localizada (Fig. 1A), situa-se nas coordenadas $1^{\circ} 41^{\prime} 33^{\prime \prime} \mathrm{S}$ e $50^{\circ} 28^{\prime} 43^{\prime \prime} \mathrm{W}$. Nesta localidade, a precipitação varia entre 2.500 a $3.000 \mathrm{~mm}$ por ano. A temperatura média equivale a $28^{\circ}$, oscilando com mínimas de $18^{\circ} \mathrm{C}$ e máximas de $36^{\circ} \mathrm{C}$. O relevo da ilha do Marajó é formado basicamente por áreas de baixio. As informações sobre cotas altimétricas presentes em mapas e cartas topográficas são escassas, havendo somente estimativas variando entre $2 \mathrm{~m}$ e $42 \mathrm{~m}$. As áreas com cotas mais elevadas mostram forte influência da altura do dossel. Modelos digitais de elevação-SRTM indicam cotas variando entre 4 e $6 \mathrm{~m}$ na porção leste da ilha, e entre 6,2 e $31 \mathrm{~m}$ em sua porção oeste, com média de $12,5 \mathrm{~m}$ (Rossetti \& Valeriano 2007).

A ilha do Marajó abrange partes das sub-bacias de Limoeiro e Mexiana, bem como da Plataforma do Pará (Fig. 1A). As sub-bacias de Limoeiro e Mexiana, juntamente com a Sub-bacia de Cametá, localizada a sudeste, são depressões formadas por falhas normais e de transcorrência inseridas em um conjunto de rifts que compõem o Sistema de Graben do Marajó (Azevedo 1991, Galvão 1991, Villegas 1994). Este cobre uma área aproximada de $1.5 \times 10^{6} \mathrm{~km}^{2}$, e consiste em uma estrutura definida por falhas orientadas para NWSE e NE-SW, além de falhas E-W a ENE-WSW e NESW, que foram reativadas a partir de estruturas antigas do embasamento pré-cambriano e cretáceo (Azevedo 1991, Villegas 1994, Costa \& Hasui 1997). Estas reativações resultam de extensão relacionada à abertura do Oceano Atlântico Equatorial, iniciado no Juro-Cretáceo (Szatmari et al. 1987). Um número crescente de trabalhos registra a permanência de atividades tectônicas nessa região durante o Cenozóico (p.e., Villegas 1994, Costa \& Hasui 1997, Costa et al. 1993, 1995, 2002, Bemerguy et al. 2002).

A área de estudo situa-se na margem oeste da Sub-bacia de Limoeiro, caracterizada por inúmeras falhas normais NW-SE com vergência principal para NE (Fig. 1A) e, subordinadamente falhas trasncorrentes NE-SW. O preenchimento sedimentar das sub-bacias de Limoeiro e Mexiana consiste em rochas cretáceas (Aptiano-Neocretáceo), representadas pelas formações Breves/Jacarezinho, Anajás e Limoeiro (Villegas 1994, Fig. 1B). Estas são sobrepostas por depósitos terciários e quaternários formados em ambiente marinho-raso a transicional, registrados pela Formação Marajó e pelo Grupo Pará (Fig. 1B). Já na Plataforma do Pará ocorrem depósitos terciários e quaternários, englobados nas formações Pirarucu e Tucunaré, mais especificamente formados a partir do Oligoceno-Mioceno. 


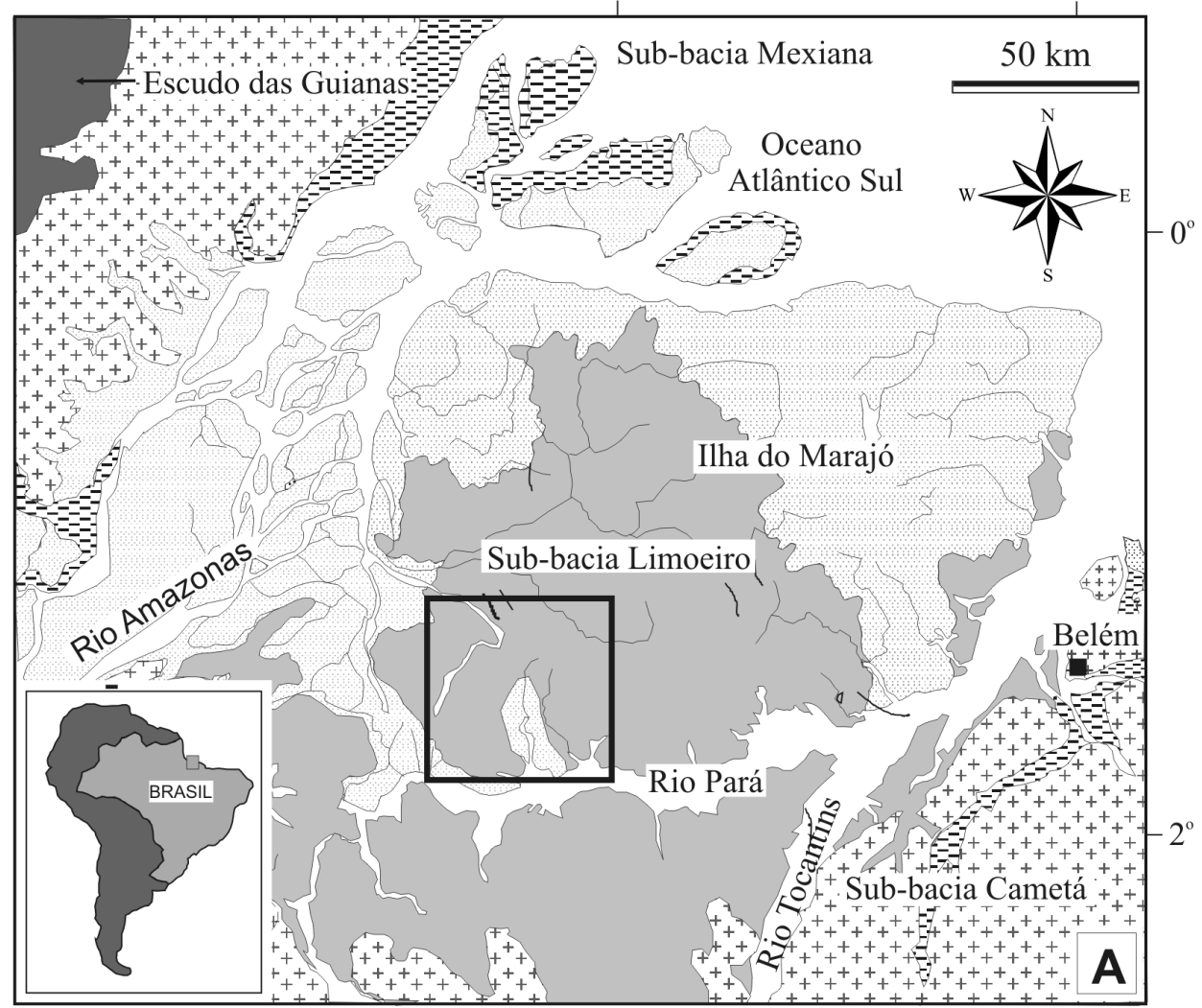

Rochas paleozóicas e pré-cambrianas

+ Rochas cretáceas e miocênicas (Formação Barreiras)

- Sedimentos Pós-Barreiras

Depósitos holocênicos

$=$ Aluviões recentes

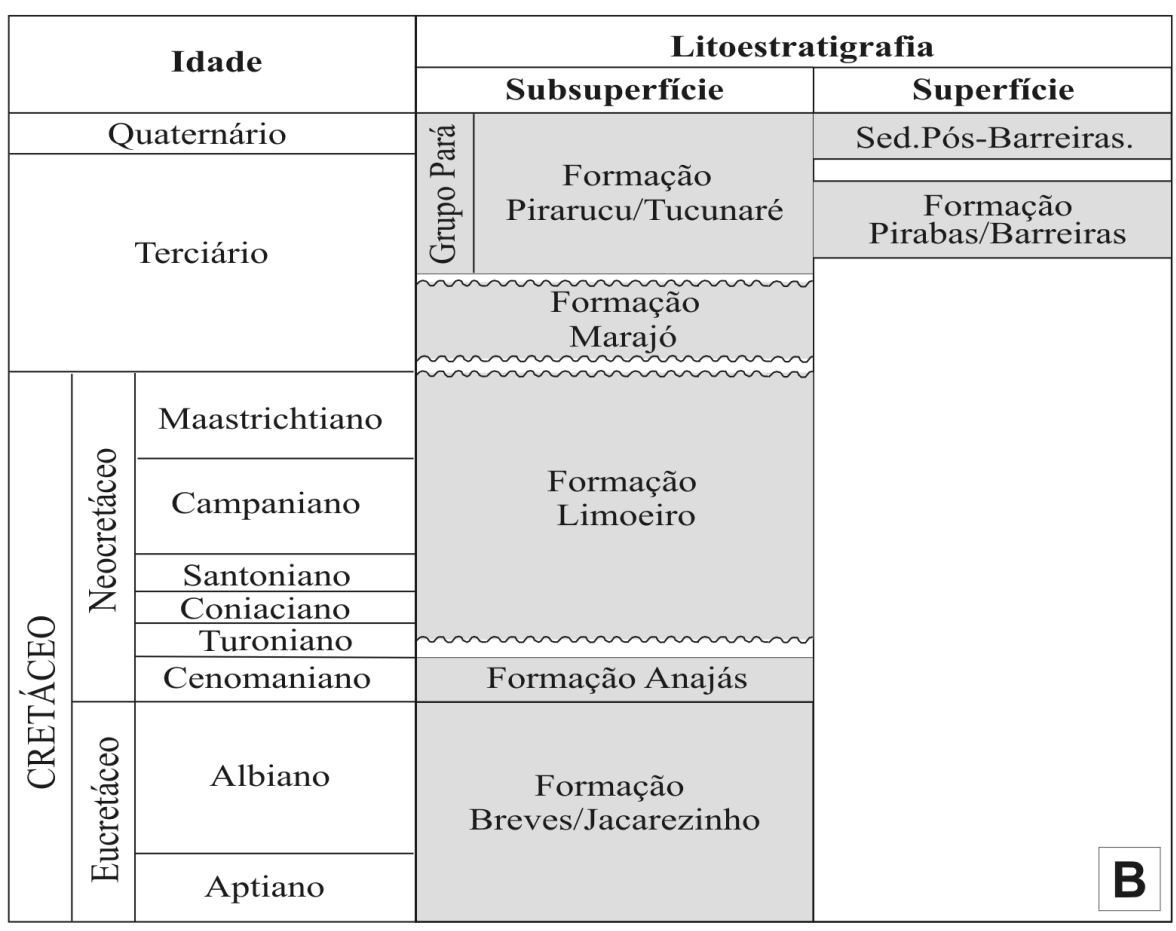

Figura 1 - A) Mapa de localização da área de estudo (ver quadro), no sudoeste da Ilha do Marajó, mostrando sua inserção na Sub-bacia do Limoeiro, na porção central do Sistema de Graben do Marajó. Notar que este graben é definido por inúmeras falhas de direção principal $N W-S E, N E-S W$, bem como E-W a ENE-WSW e NE-SW. B) Coluna estratigráfica simplificada, ilustrando as unidades litoestratigráficas depositadas na Sub-Bacia do Limoeiro. 
MATERIAIS E MÉTODOS Apresente investigação foi realizada com base em produtos cartográficos referentes à Folha SA-22 (Belém), escala 1:250.000, elaborada pelo projeto "Radar na Amazônia" (RADAM) e pelo Instituto Brasileiro de Geografia e Estatística (IBGE) . Estes dados, disponibilizados sob forma digital pelo Sistema de Proteção da Amazônia (SIPAM), foram integrados com produtos de sensoriamento remoto consistindo em dados SRTM e SAR. Os dados SRTM utilizados neste estudo foram obtidos na banda C, resolução de $90 \mathrm{~m}$ por radar interferométrico InSAR durante missão conjunta da National Aeronautics and Space Administration (NASA) e National Imagery and Mapping Agency (NIMA) em fevereiro de 2000. Estas informações são de acesso gratuito nos sites http:// edc.usgs.gov/srtm/data/obtainingdata.html ou ftp:// e0srp01u.ecs.nasa.gov/. As imagens SAR-R99B foram obtidas em levantamento aerotransportado coordenado pelo SIPAM em Outubro de 2006. O imageamento ocorreu no modo Quad L+X, com resolução de $6 \mathrm{~m}$ e polarização $\mathrm{HH}, \mathrm{HV}, \mathrm{VH}$ e VV para a banda L, e HH para a banda $X$. Do conjunto imageado, três segmentos $(18,19$ e 20$)$ foram utilizados nesse trabalho.

A extração automática da rede de drenagem foi feita no aplicativo PCI Geomatics, utilizando-se ferramentas próprias à geração de produtos de fluxo acumulado, com vetorização baseada em graus de refinamento com limiar de 25, 100 e 200. Os dados vetoriais foram devidamente ajustados para melhorar sua apresentação, com base nos aplicativos ENVI, Adobe PhotoShop e R2V. O mapa de vetor ajustado foi comparado visualmente com o mapa de drenagem disponibilizado pela IBGE/SIPAM. Além disto, foram utilizados dados SRTM originais e diferentes subprodutos obtidos da interpolação e aplicação de paletas de sombreamento no aplicativo IDRISI. Esses produtos permitiram a visualização de drenagens que não puderam ser mapeadas na base de dados anteriormente mencionada. Como resultado, procedeu-se com inúmeras edições manuais (i.e., eliminação, correção, adição) de vetores a fim de retratar, com a maior precisão possível, a drenagem da área de estudo. Por possuir resolução espacial mais refinada, as imagens SAR permitiram a vetorização desde grandes rios até de pequenos igarapés, embora o mapeamento destes não tenha sido incluído nesta escala de trabalho. Por fim, os vetores extraídos foram editados nos aplicativos AutoCad e SPRING, para ajuste de nós da rede de drenagem.

O mapa de lineamentos de drenagem foi confeccionado por extração manual tomando-se por base o mapa de drenagem obtido através do procedimento acima descrito. Os diagramas em roseta representativos das orientações dos lineamentos foram obtidos por análise automática com o aplicativo SPRING.

\section{RESULTADOS}

Mapa de drenagem Considerando-se o grande esforço que representa a elaboração manual de mapas de drenagem, testou-se o método de extração automática da drenagem atual. Em geral, os mapas produzidos com graus de refinamento de 25, 100 e 200, em ordem decrescente de detalhamento (Fig. 2A-C), registraram drenagens mais detalhadas do que o mapa do IBGE/SIVAM (Fig. 2D). O mapa com refinamento de 200 (Fig. 2C) foi o que mais se aproximou do mapa do IBGE. Entretanto, inúmeras drenagens de classes hierárquicas inferiores (i.e., correspondentes a pequenos distributários) não foram detectadas neste mapa. Já o mapa com refinamento de 25 resultou em uma abundância de drenagens nas classes hierárquicas mais inferiores, que não foram confirmadas em uma análise detalhada dos produtos processados SRTM.

Tendo-se em vista os resultados incompletos alcançados com a extração automática, selecionou-se o mapa mais representativo da drenagem da área de estudo, neste caso o de refinamento 100 , como base no traçado final, feito manualmente (Fig. 3). Este produto serviu para uma análise comparativa com o mapa do IBGE/SIVAM, bem como com vários outros subprodutos processados com base nos dados SRTM. As imagens SAR, auxiliaram neste processo, possibilitando a confirmação de grande parte das drenagens principais. Dada sua resolução de $6 \mathrm{~m}$, este tipo de produto permite a visualização de hierarquias de drenagem de classes mais inferiores que não são passíveis de reconhecimento nos outros dados utilizados para a geração do mapa de drenagem final, tendo sido, portanto, desconsideradas neste estudo.

Caracterização das bacias de drenagem A análise do mapa de drenagem atual revelou que a área de estudo é, em geral, variável e complexa, com densidade e padrões de drenagem que mostram forte controle tectônico, como será discutido na seqüência deste trabalho. A densidade de drenagem varia de muito baixa a muito alta. Os padrões de drenagem, em ordem decrescente de abundância, incluem: sub-dendrítico, retangular/angular, palimpsesto, sub-paralelo, sub-treliça, radial anelar e treliça (Fig. 4A). A distribuição desses padrões, bem como a caracterização de outras propriedades de drenagem relevantes, são melhor descritas no contexto das seis bacias hidrográficas reconhecidas na área de estudo que, em ordem decrescente de grandeza, incluem: Bacia rios Macaco-Breves-Buruçú, Bacia rios Guajará-Curuaçá, Bacia rios Mucuta-Mutuacá, Bacia rio Mapuá, Bacia rio Rapariga, e Bacia rios Jaburuzinho-Piranha (Fig. 4B). Várias das principais bacias de drenagem têm seus cursos d'água principais finalizando no rio Pará, que delimita a porção sul da área de estudo.

BACIA RIOS MACACO-BREVES-BURUÇÚ Esta é a maior bacia hidrográfica da área de estudo, ocorrendo em grande parte de sua porção ocidental, onde perfaz uma área total de aproximadamente $1.760 \mathrm{~km}^{2}$. Os cursos d'água são bastante variáveis. No extremo nordeste da bacia, o rio Macaco apresenta várias mudanças de direção, sendo estas, de montante a jusante, de NW para SE, SW, NW e daí para SW. É interessante notar que todas essas mudanças de cursos são súbitas, com ângulos de inflexão de $90^{\circ}$, formando um retângulo aberto 


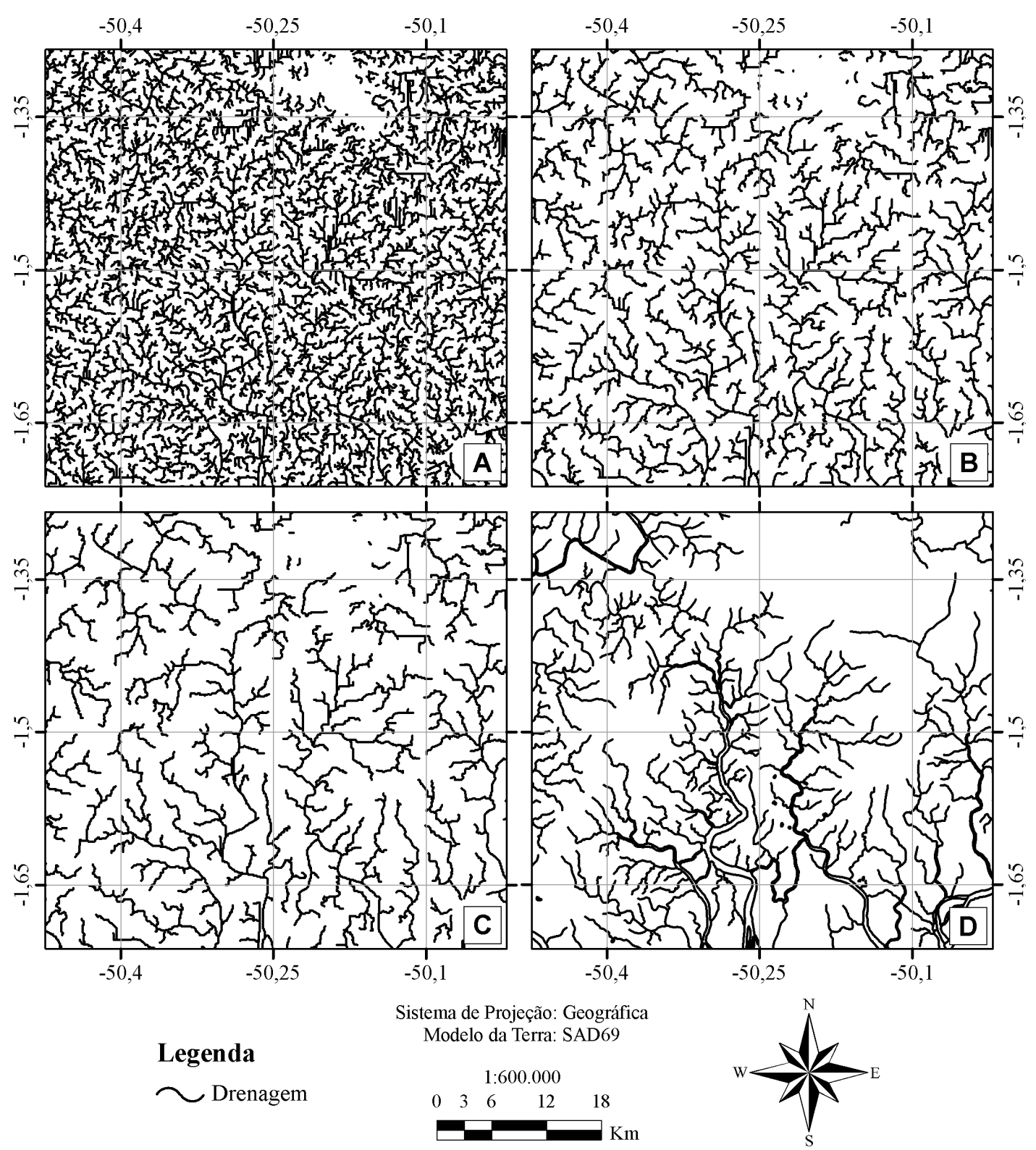

Figura 2 - A-C) Mapas de drenagem obtidos automaticamente para parte da área de estudo, utilizando-se o aplicativo PCI Geomatics, considerando graus de refinamento progressivos de 25 (A) , 100 (B) e 200 (C). D) Mapa de drenagem do IBGE/ SIVAM, para comparação.

para noroeste. Após se estender na direção NE-SW por cerca de aproximadamente $32 \mathrm{~km}$, o rio Macaco volta a sofrer uma súbita inflexão, novamente em ângulo reto, para SE. A densidade de drenagem é, em geral, média, ocorrendo pequenas áreas com densidade alta e, subordinadamente, muito alta. O padrão dominante é do tipo sub-dendrítico, com junção de canais mostrando ângulos que variam de agudo a reto. A nordeste da bacia, na parte interna da feição em retângulo aberto formada pelo rio principal, domina drenagem angular. Além disto, ocorrem três pequenas áreas, duas à direita e uma à esquerda do rio Macaco, onde a drenagem configura padrão radial anelar. Para sul, a bacia é dominada pelo rios Breves e Furo Buruçú, e seus tributários, onde tanto a densidade, quanto o padrão de drenagem mudam. Assim, a densidade varia de média a baixa e muito baixa, enquanto que o padrão de drenagem varia dos tipos sub-treliça a sub-paralelo, com pequena área apresentando padrão retangular.

\section{BACIA RIOS GUAJARÁ-CURUAÇÁ Da mesma ma-} neira que o rio Macaco-Breves-Buruçú, os rios Guajará e Curuaçá definem uma importante bacia de drenagem, com área aproximada de $850 \mathrm{~km}^{2}$. Esses cursos d'água fluem dominantemente de norte para sul, onde deságuam no rio Pará. A densidade de drenagem é, em geral, média, e localmente baixa a muito baixa. Os canais no entorno do médio e baixo cursos de ambos os rios estão organizados de forma a configurar padrão dos tipos retangular a angular e, subordinadamente, sub-paralelo. 


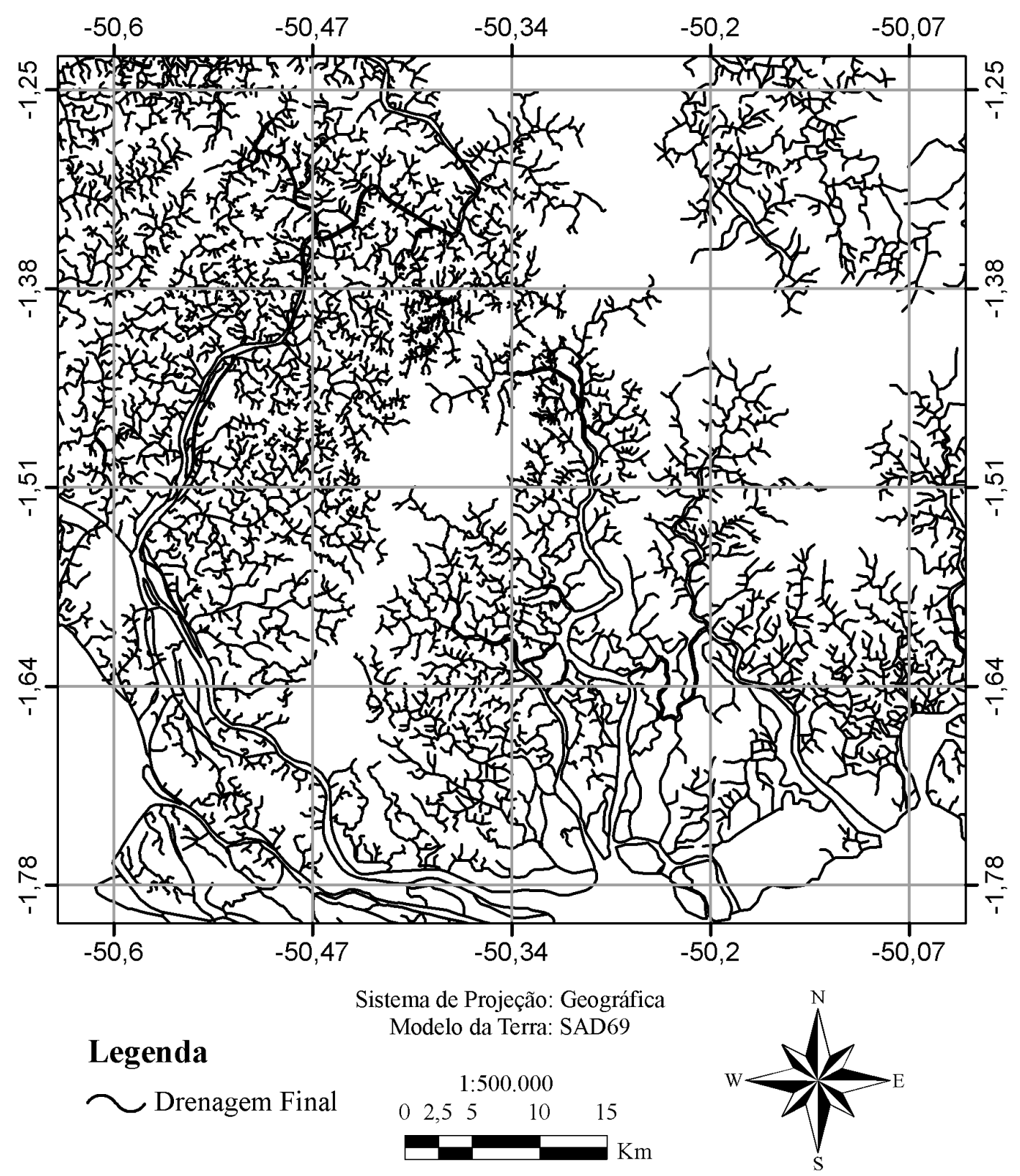

Figura 3 - Mapa final da rede de drenagem atual da área de estudo, tomando-se por base extração automática com grau de refinamento de 100. Este mapa incorpora inúmeras modificações de vetores feitas através de comparações com imagens SAR, bem como com subprodutos SRTM, a fim de melhorar a precisão do traçado.

No alto curso do rio Guajará nota-se, ainda, pequena área com padrão radial anelar. Ressalta-se que o rio Guajará possui uma grande anomalia de drenagem em seu médio curso, definida por meandramento localizado, que passa rapidamente, à jusante, para canal retilíneo. Essa anomalia de drenagem é refletida no curso do rio Curuaçá, que também apresenta pequeno meandro localizado na mesma latitude daquela do rio Guajará. É interessante observar que estas anomalias de drenagem ocorrem em associação ao padrão de drenagem retangular a angular.

BACIA RIOS MUCUTÁ-MUTUACÁ Esta bacia domina a porção sudeste da área de estudo, onde perfaz uma área aproximada de $795 \mathrm{~km}^{2}$. O direcionamento do fluxo principal no rio Mucutá varia de N/NE para $\mathrm{S} / \mathrm{SW}$ até sua porção mediana, onde ocorre rápida inflexão para SE, enquanto no rio Mutuacá é de N para $\mathrm{S}$. A densidade de drenagem é dominantemente média, porém com áreas localizadas onde a densidade é alta ou baixa a muito baixa. Como ocorre na bacia dos rios Gujará-Curuaçá, o padrão de drenagem prevalecente é sub-dendrítico, verificado em toda a área no entorno do rio Mutuacá e à direita do rio Mucutá. À esquerda desse rio, o padrão é do tipo retangular a angular. Ainda similarmente à bacia dos rios Guajará-Curuaçá, as porções medianas de ambos os rios principais dessa bacia 


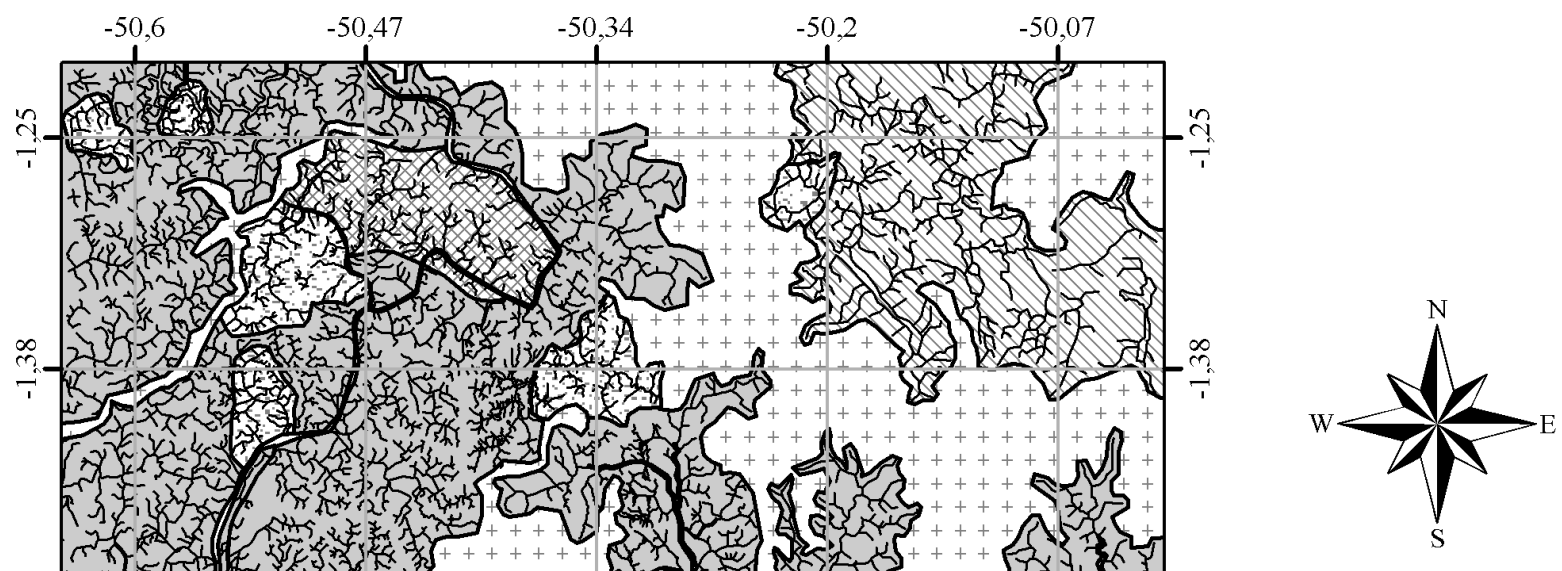

\section{Legenda}
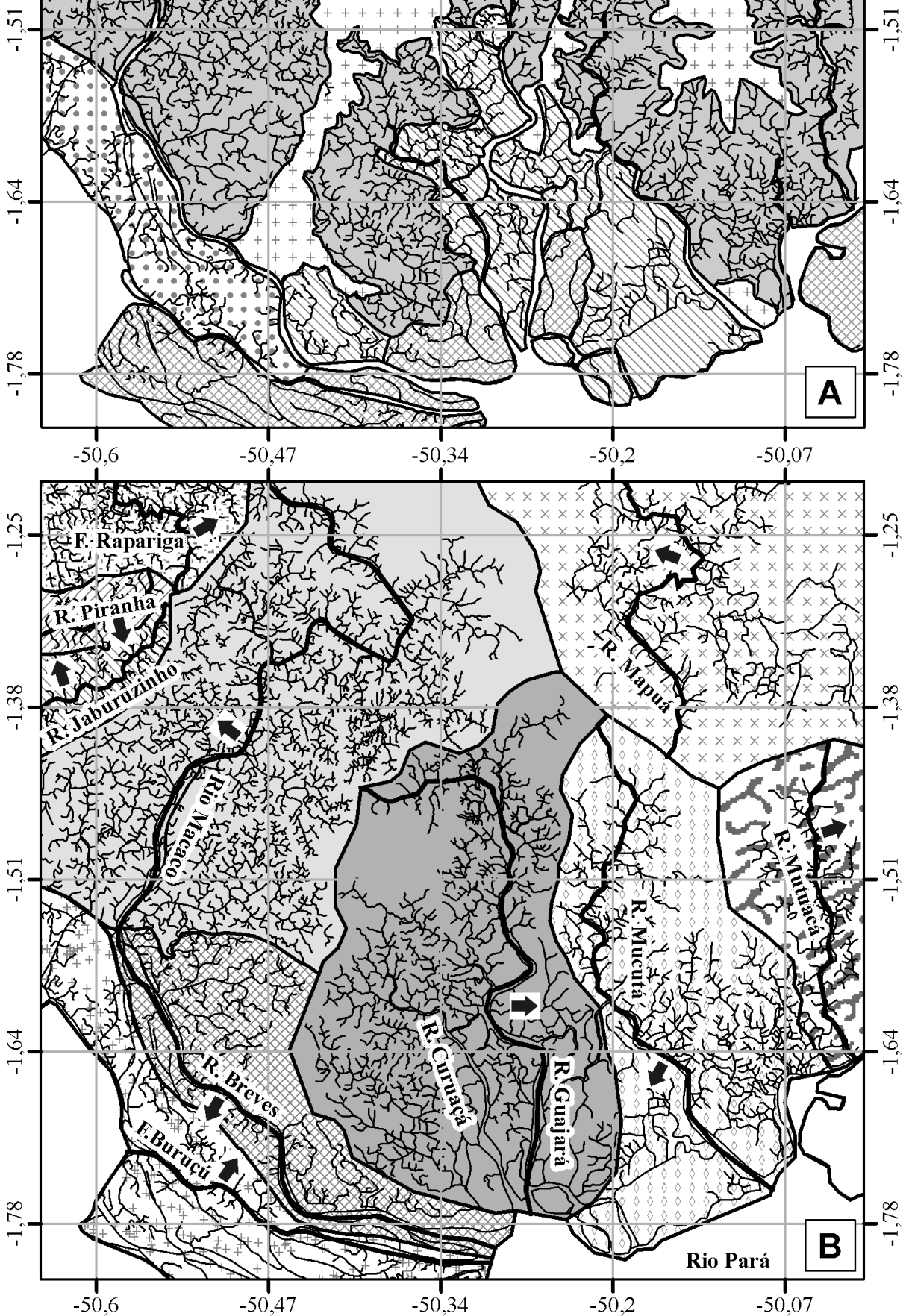

$\sim$ Drenagens Principais

$\frown$ Drenagem final

Padrões de drenagem

Radial anelar

DIV Retangular / angular

$\square$ Sub-dendrítico

Sub-paralelo

$\because \because$ Sub-treliça

Treliça

++
++ Palimpsesta

$\square$ Água

Sub-bacias de Drenagem

Furo da Rapariga

EIA Rio Piranha

MIV Rio Jaburuzinho

$\square$ Rio Macaco

Rio de Breves

$++_{++}^{+}$Furo Buruçú

$\square$ Rio Guajará

Rio Mucutá

¿ Rio Mutuacá

$x \begin{aligned} & x \\ & x \times y \\ & x\end{aligned}$

$\square$ Outras Bacias

Sistema de Projeção: Geográfica Modelo da Terra: SAD69 $1: 600.000$

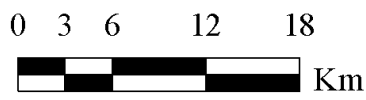

Figura 4 - Mapa de drenagem da área de estudo contendo: A) A distribuição dos padrões de drenagem. B) A distribuição das bacias de drenagem (setas apontam o sentido de basculamento do terreno, indicado pelo fator de assimetria). 
hidrográfica são dominadas por uma série de meandros localizados, alguns dos quais com mudanças rápidas de cursos, formando ângulos retos. À jusante dos trechos meandrantes, estes rios tornam-se retilíneos.

BACIA RIO MAPUÁ Esta bacia hidrográfica localizase no extremo nordeste da área de estudo, onde perfaz cerca de $510 \mathrm{~km}^{2}$. De modo geral, o direcionamento dos cursos d'água é bastante variável, o que dificulta a identificação de uma direção preferencial para seu fluxo. No entanto, diferentemente das bacias hidrográficas anteriormente descritas, percebe-se fluxo principal de SE para NW, com rápida inflexão de aproximadamente $90^{\circ}$ para NE. A densidade da drenagem é, em geral, baixa a média. O padrão é uniforme, sendo dominantemente do tipo retangular a angular, com pequena área com drenagem radial anelar no oeste dessa bacia. Uma feição interessante, que se constitui em anomalia de drenagem, é representada pelo súbito alargamento do rio Mapuá em sua porção mais superior. Adicionalmente, neste trecho o canal é fortemente retilíneo, o que contrasta com seu curso à jusante, onde ele se torna relativamente mais sinuoso. Alagamento similar, porém de menor extensão, ocorre no extremo sudeste dessa bacia hidrográfica.

BACIA FURO DA RAPARIGA Esta bacia está localizada no extremo noroeste da área de estudo, onde perfaz uma área de cerca de $156 \mathrm{~km}^{2}$. Este curso d'água apresenta uma série de alterações de direção, sendo o mais meandrante relativamente aos cursos d'água principais das demais bacias hidrográficas estudadas. De forma geral, ocorrem dois fluxos principais, um de $\mathrm{N}$ para $\mathrm{S}$, e outro de $\mathrm{S}$ para $\mathrm{N}$, que se encontram para formar canal com fluxo de $\mathrm{E}$ para $\mathrm{W}$, e daí para N. A densidade de drenagem é, em geral, média a alta e o padrão principal é do tipo sub-dendrítico. Entretanto, duas áreas anômalas com padrão de drenagem radial anelar acham-se presentes, uma no centro da bacia e outro em sua porção oeste.

BACIA RIOS JABURUZINHO-PIRANHA Estes dois rios ocorrem na porção noroeste da área de estudo, imediatamente a sul da bacia do furo da Rapariga, onde definem bacia hidrográfica que se estende por uma área de aproximadamente $131 \mathrm{~km}^{2}$, sendo, portanto, a menor descrita neste trabalho. Os rios Jaburuzinho e Piranha possuem seus cursos d'água bem definidos, direcionados de NE para SW e S/SW, respectivamente. Relativamente a este rio, o rio Jaburuzinho possui curso mais sinuoso, além de mostrar hierarquia de drenagem mais complexa, embora, de modo geral, ambas as drenagens sejam hierarquicamente bem mais simples relativamente às outras bacias hidrográficas da área de estudo. A densidade de drenagem é média, e o padrão dominante é exclusivamente do tipo sub-dendrítico, com freqüentes junções de canais em ângulos retos, particularmente em associação com o rio Piranha.

Lineamentos estruturais A análise da rede de drenagem da área de estudo revelou inúmeros canais retilíneos, que se destacam das demais drenagens, definindo lineamentos morfoestruturais (O'Leary et al. 1976). Em combinação com anomalias de drenagem, já descritas acima, esses foram mapeados com o objetivo de subsidiar discussões sobre o controle tectônico no desenvolvimento das bacias hidrográficas (Fig. 5A). Os dados estatísticos (Tab. 1) e os diagramas em roseta (Fig. 5B-C), resultante desse processamento, indicam lineamentos principais nas direções NW-SE e NE-SW, havendo modas secundárias nas direções NNW-SSW e E-W. As distribuições, tanto das freqüências dos lineamentos (Fig. 5B), quanto dos comprimentos acumulados (Fig. 5C), para toda a região, indicam os seguintes grupos, em ordem decrescente de

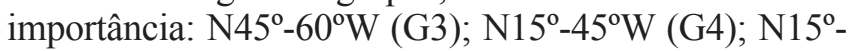
$60^{\circ} \mathrm{E}(\mathrm{G} 7) ; \mathrm{N} 60^{\circ}-75^{\circ} \mathrm{W}(\mathrm{G} 2) ; \mathrm{N} 0^{\circ}-15^{\circ} \mathrm{E}(\mathrm{G} 6) ; \mathrm{N} 60^{\circ}-75^{\circ} \mathrm{E}$ (G7); $\mathrm{N}^{\circ}-15^{\circ} \mathrm{W}$ (G5) e E-W (G1). A semelhança ve-

Tabela 1 - Dados estatísticos dos lineamentos morfoestruturais gerados para a área de estudo, subdivididos em intervalos de $15^{\circ}$.

\begin{tabular}{c|c|c|c|c|c|c}
\hline \multicolumn{2}{c|}{$\begin{array}{c}\text { Início e fim do } \\
\text { segmento } \\
\text { (graus) }\end{array}$} & $\begin{array}{c}\text { Freqüência } \\
\text { Absoluta } \\
(\%)\end{array}$ & $\begin{array}{c}\text { Comprimento } \\
\text { Absoluto } \\
(\mathrm{km})\end{array}$ & $\begin{array}{c}\text { Freqüência } \\
\text { Relativa } \\
(\%)\end{array}$ & $\begin{array}{c}\text { Comprimento } \\
\text { Relativo } \\
(\mathrm{km})\end{array}$ & $\begin{array}{c}\text { Comprimento } \\
\text { Médio } \\
(\mathrm{km})\end{array}$ \\
\hline $0-$ & 15 & 39 & 57,57 & 3,79 & 4,42 & 1,48 \\
$15-$ & 30 & 62 & 66,00 & 6,03 & 5,06 & 1,06 \\
$30-$ & 45 & 103 & 113,49 & 10,02 & 8,71 & 1,10 \\
$45-$ & 60 & 101 & 117,16 & 9,82 & 8,99 & 1,16 \\
$60-$ & 75 & 96 & 128,59 & 9,34 & 9,87 & 1,34 \\
$75-$ & 90 & 79 & 109,91 & 7,68 & 8,43 & 1,39 \\
$90-$ & 105 & 50 & 59,72 & 4,86 & 4,58 & 1,19 \\
$105-$ & 120 & 94 & 125,58 & 9,14 & 9,64 & 1,34 \\
$120-$ & 135 & 113 & 149,95 & 10,99 & 11,51 & 1,33 \\
$135-$ & 150 & 142 & 180,98 & 13,81 & 13,89 & 1,27 \\
$150-$ & 165 & 96 & 118,01 & 9,34 & 9,06 & 1,23 \\
$165-$ & 180 & 53 & 76,21 & 5,16 & 5,85 & 1,44 \\
\hline
\end{tabular}



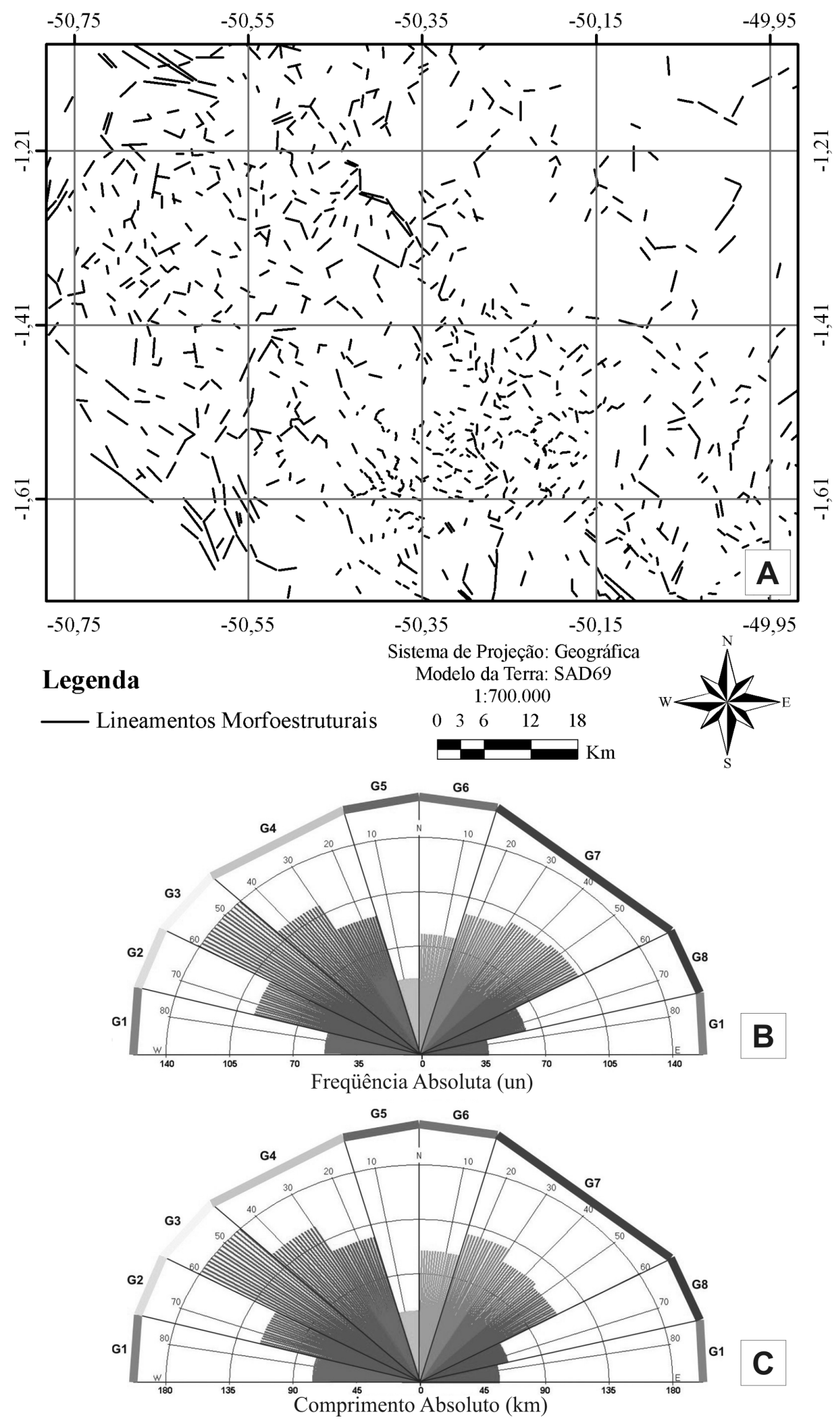

Figura 5 - Lineamentos morfoestruturais da área de estudo. A) Mapa dos lineamentos obtidos a partir de segmentos de drenagem retilineos a levemente curvos, que diferem do padrão geral dos canais da área. B) Diagrama em roseta com a orientação dos lineamentos obtidos com base em sua freqüência absoluta. C) Diagrama em roseta com a orientação dos lineamentos obtidos com base em seus comprimentos acumulados. 
rificada entre os diagramas em roseta construídos com relação à freqüência e ao comprimento absoluto reflete consistência nas direções dos lineamentos morfoestruturais reconhecidos na área de estudo.

Alguns lineamentos merecem destaque, sendo estes os de direção NNE-SSW caracterizados em longos trechos do rio Macaco, baixo curso do rio Guajará e alto curso do rio Mucutá. Juntamente com estes, destacam-se, também, os lineamentos de direção NW/ $\mathrm{SE}$ dos rios Breves, que é seguido por vários afluentes paralelos de sua margem direita. Além disto, lineamentos com esta última direção definem o curso principal do rio Mucutá, bem como trechos altos dos rios Macaco e Mapuá.

Assimetria das bacias de drenagem Visando a complementação de dados que possibilite uma análise adequada do controle tectônico na área de estudo, além da caracterização dos lineamentos e anomalias de drenagem, calculou-se, também, o fator de assimetria considerando-se os principais rios das bacias hidrográficas. Este fator é de grande aplicação no reconhecimento de terrenos que tenham sofrido basculamentos, podendo indicar o sentido das movimentações (Fig. 4B) (Keller \& Pinter 1996). O cálculo da assimetria de bacias de drenagem é feito utilizando-se a fórmula: $\mathrm{AF}=100 \mathrm{x}(\mathrm{Ad} / \mathrm{At})$, onde $\mathrm{AF}=$ fator de assimetria, $\mathrm{Ad}=$ área direita da bacia de drenagem, e At=área total da bacia de drenagem.

$O$ resultado aplicado às principais bacias de drenagem da área de estudo (Tab. 2) revelou que a principal bacia, representada pelos rios Macaco, Breves e Buruçú, varia de fortemente assimétrica a simétrica. Isto é indicado por $\mathrm{AF}=38,25$ para o rio Macaco, o que reflete área menor à direita da bacia. Para o rio Breves, $\mathrm{AF}=22,98$ indica área da bacia relativamente bem maior à esquerda do rio. Para o Furo Buruçú, $\mathrm{AF}=51,63$ revela bacia aproximadamente simétrica. Similarmente, a bacia dos rios Guajará e Mucutá, segunda principal da área de estudo, apresentam valores de $\mathrm{AF}=63,66$ e 38,33, em função de suas áreas menores à esquerda e direita destes rios, respectivamente. A bacia de maior assimetria é a do rio Mapuá, com $\mathrm{AF}=65,40$, que possui área à esquerda do rio relativamente bem menor que em sua direita. As demais bacias de drenagem são simétricas a aproximadamente simétricas, sendo indicadas por valores de $\mathrm{AF}=61,24$, 38,60 , 46,23, e 55,96 para as bacias dos rios Mucutá, Rapariga, Jaburuzinho e Piranha, respectivamente.

\section{DISCUSSÃO}

Eficiência da extração automática da drenagem De modo geral, modelos digitais de elevação baseados em dados SRTM constituem-se em ferramenta de grande auxílio no estudo de drenagens atuais. Além de fornecer subsídios para uma análise visual detalhada, esses dados podem ser usados em processamentos automáticos de extração da rede de drenagem (Jenson \& Domingue 1988, Deffontaines \& Chorowicz 1991, Martz \& Garbrecht 1992, Curkendall et al. 2003, Jordan et al. 2005), otimizando, de forma substancial, o tempo empregado nesta tarefa. Em áreas de relevos acentuados e, portanto,
Tabela 2 - Área total, área da margem direita (MD) e fator de assimetria das principais bacias de drenagem da área de estudo.

\begin{tabular}{l|c|c|c}
\hline \multicolumn{1}{c|}{ BACIA } & $\begin{array}{c}\text { Área total } \\
\mathrm{Km}^{2}\end{array}$ & $\begin{array}{c}\text { Área Margem } \\
\text { Direita } \\
\mathrm{Km}^{2}\end{array}$ & $\begin{array}{c}\text { Fator de } \\
\text { Assimetria (AF) }\end{array}$ \\
\hline Furo da Rapariga & 156,02 & 60,22 & 38,60 \\
Rio Piranha & 56,32 & 31,52 & 55,96 \\
Rio Jaburuzinho & 75,32 & 34,82 & 46,23 \\
Rio Macaco & 1123,51 & 429,78 & 38,25 \\
Rio Breves & 349,23 & 80,27 & 22,98 \\
Furo Buruçú & 372,12 & 192,13 & 51,63 \\
Rio Guajará & 875,43 & 557,33 & 63,66 \\
Rio Mucuta & 643,88 & 246,81 & 38,33 \\
Rio Mutuacá & 247,46 & 151,54 & 61,24 \\
Rio Mapuá & 660,38 & 431,86 & 65,40 \\
\hline
\end{tabular}

vales bem definidos, este procedimento pode ser irrelevante. Porém, sua utilização em áreas de baixas topografias, como é o caso da Amazônia, pode resultar em produtos pouco satisfatórios.

Embora estudos anteriores tenham demonstrado grande sucesso em extrações automáticas de drenagem na Amazônia (Martins et al. 2005), o presente estudo mostrou resultados que, por si só, são inadequados para representar a rede de drenagem da área de estudo com precisão. Por comparação visual com os dados SRTM, pode-se observar que a extração automática introduziu uma abundância de canais nas classes hierárquicas mais inferiores, que não têm correspondência com drenagens verdadeiras. Este resultado foi relacionado ao fato da área de estudo não possuir gradientes de altitudes significativos, sendo representada por médias de apenas 12,5 $\mathrm{m}$. O relevo dominantemente plano e extremamente baixo e, portanto, sem definição clara de vales, faz com que os sistemas utilizados sejam inaptos ao reconhecimento de drenagens em classes hierárquicas inferiores, ocasionando um problema que é resolvido, de forma errônea, com a geração de inúmeras drenagens artificiais. Resultado bastante similar foi obtido para a região do rio Uatumá, na Bacia do Amazonas (Ibanez 2006).

Portanto, os dados obtidos da extração automática de drenagem apontam para a necessidade de geração de mapas de drenagem, no caso de áreas de relevo extremamente baixo, ainda por métodos tradicionais manuais, como feito no presente trabalho.

Significado geológico dos lineamentos Uma variedade de elementos de drenagem leva a interpretar que os lineamentos morfoestruturais da região de Breves são relacionados com estruturas tectônicas. Entre estes, destacam-se: 1. domínio de padrão sub-dendrítico, caracterizado por abundância de canais retilíneos e com junções em ângulos elevados, comumente chegando a $90^{\circ} ; 2$. abundância de padrão angular e, subordinadamente, sub-treliça e sub-paralelo, onde predominam 
canais retilíneos, muitas vezes com junções em ângulos retos (no caso dos dois primeiros padrões); 3. rápida mudança de padrão dentro da mesma bacia de drenagem; 4. ocorrência de padrão retangular; 5. rápidas mudanças de curso em ângulos de $90^{\circ}$, como verificado no alto rio Macaco, onde o canal forma feição retangular; 6. ocorrência de meandramento localizado em canal dominantemente retilíneo, como verificado principalmente nos rios Guajará e Curuaçá, bem como Mucutá e Mutuacá; e 7. súbito alargamento de canais, como registrado na bacia do rio Mapuá. Vários autores relacionam essas feições de drenagem com estruturas tectônicas (p.e., Doornkamp 1986, Deffontaines \& Chorowicz 1991, Berger 1994, Potter 1997).

Adicionalmente, a semelhança verificada entre os diagramas em roseta com relação à freqüência e ao comprimento absoluto indica consistência nas direções dos lineamentos morfoestruturais verificados na área de estudo. A comparação com dados de literatura revela que a orientação dos lineamentos principais na região de Breves mostra grande consistência com a orientação de lineamentos tectônicos prevalecentes na região Amazônia. Assim, Szatmari et al. (1987) mapearam um sistema de falhas transcorrentes na bacia do baixo Rio Amazonas de direção dominante NE-SW. Estas falhas refletem estruturas formadas no Neocretáceo (Azevedo 1991, Galvão 1991, Villegas 1994, Bezerra 2003), que sofreram várias reativações, até mesmo no período Quaternário. Costa et al. (1995, 1996, 1997, 2001), Potter (1997) e Bemerguy et al. (2002) ressaltaram a importância de lineamentos estruturais, tanto de direção NW-SE, quanto de direção NE-SW, no arcabouço tectônico cenozóico da Amazônia. Mais recentemente, estudo desenvolvido por Silva et al. (2007) em uma área localizada na porção oeste da Bacia do Amazonas, salienta a importância de lineamentos tectônicos de direções principais NE-SW, NW-SE. Para esses autores, estas estruturas estão associadas às falhas limitantes de estruturas do tipo horst e graben alternados. Adicionalmente, Almeida-Filho \& Miranda (2007) também registraram uma mega-captura do rio Negro na Amazônia Central, ocorrida pela reativação de falhas de direção NW-SE. A maioria dos autores supracitados registrou lineamentos tectônicos subordinados de direção E-W e $\mathrm{N}-\mathrm{S}$, que também estariam relacionados com reativações de falhas transcorrentes.

É interessante notar, ainda, que a orientação dos lineamentos tectônicos na região de Breves segue o direcionamento de outros lineamentos morfoestruturais relacionados a reativações de falhas no leste da ilha do Marajó, e áreas adjacentes. Rossetti \& Valeriano (2007), identificaram um amplo paleovale, que se estende desde a cidade de Tucuruí, no baixo rio Tocantins, até a ilha do Marajó cujas margens são definidas por falhas NNW-SSE e NE-SW. As modas principais dos lineamentos morfoestruturais NW-SE e NE-SW, mapeados para a área de estudo, são consistentes com aquelas registradas na porção leste da ilha do Marajó, onde dominam direções NE-SW, NW-SE, NNE-SSW (Azevedo 1991, Galvão 1991, Villegas 1994, Bezerra 2003, Ros- setti \& Valeriano 2007, Rossetti et al. 2008a).

A apresentação de um modelo tectônico para a área de estudo está além dos objetivos deste trabalho. Porém, tomando-se por base as informações disponíveis na literatura, pode-se sugerir que os lineamentos morfoestruturais de direção NE-SW e NW-SE, dominantes na região de Breves, estão muito provavelmente relacionados aos mesmos eventos de reativações de falhas tectônicas que teriam dominado grande parte da Amazônia durante o Cenozóico. Similarmente, os lineamentos de direção E-W estariam associados com eventos subordinados de reativações de falhas, que são também detectados em muitas outras áreas dessa região.

O comportamento tectônico sugerido pelos lineamentos morfoestruturais extraídos da rede de drenagem são condizentes com o contexto tectônico da Sub-bacia do Limoeiro. Como previamente descrito, esta sub-bacia faz parte do Sistema de Graben do Marajó, estando localizada em sua porção central. A área de estudo situa-se na margem oeste desta sub-bacia, que é definida por conjuntos de falha de direção principal NW-SE, com mergulhos dominantes para NE, embora ocorram, também, mergulhos para SW. Estas falhas são bem registradas não só em superfície, como também em sub-superfície, com base em dados de sísmica (Galvão 1991). De acordo com este autor, outros lineamentos de direção NE-SW, e aproximadamente E-W, estão presentes na área. Considerando-se que o terreno estudado é de idade quaternária, pode-se concluir que o estabelecimento do sistema de drenagem atual foi fortemente controlado por zonas de fraqueza representadas por falhas tectônicas reativadas durante este período geológico.

O forte controle tectônico na área de Breves pode ser evidenciado, ainda, pelo fator de assimetria das bacias de drenagem. Isto porque, bacias muito assimétricas, ou seja, bacias com valores de AF muito inferiores ou muito superiores a 50, têm grande probabilidade de serem tectonicamente controladas. Assim, tem-se sugerido basculamento para a esquerda de uma bacia se $\mathrm{AF}>50$, e para a sua direita se $\mathrm{AF}<50$ (Keller \& Pinter 1996). Adicionados à presença das outras feições de drenagem sugestivas de controle tectônico, como relacionadas acima, os valores de AF bem acima de 50 nas bacias dos rios Guajará, Mutuacá, Mapuá, refletem áreas maiores à direita desses rios, sugerindo basculamentos para a esquerda (Fig. 4). Valores de AF bem abaixo de 50 são verificados nos rios Macaco, Breves, Mucutá e Rapariga, onde as áreas maiores acham-se à esquerda dos rios, sugerindo basculamentos para a direita.

Dentre os rios principais, o rio Breves e o Furo Buruçú são os que melhor refletem as falhas principais NW-SE que delimitam a borda oeste da Sub-bacia do Limoeiro. No caso particular do rio Breves, a indicação de basculamento para a direita do rio é consistente com mergulho de plano de falha para NE, como registrado mais comumente nos dados sísmicos dessa área. Da mesma forma, o rio Macaco acha-se orientado de acordo com as falhas de direção NE-SW, com caimento do plano para SE. É interessante notar, entretanto, 
que os demais rios principais, i.e., o Guajará, Mucutá Mutuacá e Mapuá, não seguem a orientação dessas falhas da bacia. A orientação desses rios na direção geral NNW-SSE, formando sistemas paralelos, sugere influência de outros conjuntos de falhas na área de estudo. Ressalta-se que este direcionamento coincide com a orientação geral da feição morfológica representativa do paleovale quaternário formado entre a cidade de Tucuruí e a ilha do Marajó, como acima referenciado. O basculamento para a esquerda no rio Guajará, e para a direita no rio Mucutá, levanta a hipótese de que a área entre estes rios tenha se elevado relativamente às áreas adjacentes. A figura 6 ilustra esta situação, considerando-se um contexto tectônico dominado por falhas, como o sugerido para a área de estudo.

CONCLUSÕES A utilização de ferramentas de sensoriamento remoto para extração da rede de drenagem atual da área de estudo mostrou que, apesar de fornecer esse produto de forma bastante eficiente, para área de relevos muito baixos, ainda é necessária a digitalização manual através da integração de modelos digitais de elevação SRTM, seus subprodutos, e dados SAR. Este tipo de integração de dados resulta em mapas de drenagem de maior fidedignidade, adequados para o tipo de interpretação morfoestrutural realizada no presente estudo.

Por meio da interpretação dos lineamentos morfoestruturais baseada na rede de drenagem atual, foi possível concluir que o desenvolvimento da paisagem no sudoeste da ilha do Marajó é controlado por fator tectônico, como anteriormente sugerido para sua porção leste. Com base nos dados apresentados, pode-

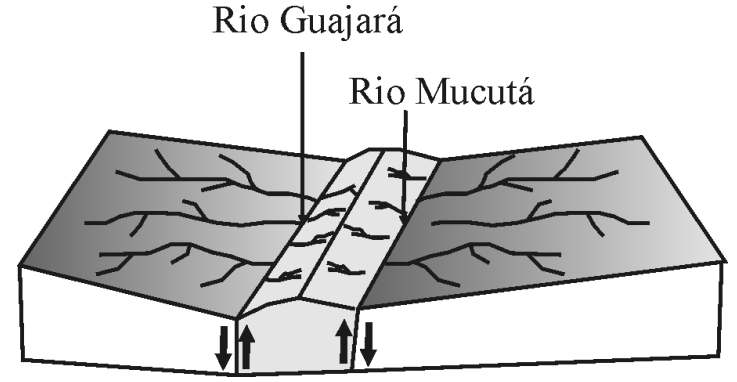

Figura 6 - Basculamento para a esquerda no rio Guajará, e para a direita no rio Mucutá, levanta a hipótese de que a área entre estes rios tenha se elevado relativamente às áreas adjacentes, considerando-se contexto tectônico dominado por falhas, como o sugerido para a área de estudo.

se concluir que a ilha do Marajó manteve-se tectonicamente instável durante o Pleistoceno tardio e Holoceno devido à reativação de falhas pré-existentes. Este processo representa um importante fator na criação de espaço para acomodação de sedimentos desta idade na ilha do Marajó.

Agradecimentos Este trabalho foi financiado pela FAPESP (Projeto \#004/15518-6). Os autores agradecem o apoio logístico do INPE durante a execução da pesquisa, e ao Dr. M.M.Valeriano pelo auxílio em algumas fases do processamento de dados SRTM.

\section{Referências}

Almeida-Filho R. \& Miranda F.P. 2007. Mega capture of the Rio Negro and formation of the Anavilhanas Archipelago, Central Amazônia, Brazil: Evidences in an SRTM digital elevation model. Rem Sens Envir, 110:387-392.

Azevedo R.P. 1991. Tectonic evolution of Brazilian Equatorial Continental Margin Basins. Tese de Doutoramento, University of London, 455p.

Berger Z. 1994. Satellite Hydrocarbon Exploration: Interpretation and Integration Techniques. Berlin: SpringerVerlag-Heidelberg, 319p.

Bezerra P.E.L. 2003. Compartimentação morfotectônica do interflúvio Solimões-Negro. Tese de Doutoramento, Universidade Federal do Pará, 335p.

Bemerguy R.L. 1981. Estudo sedimentológico dos paleocanais da região do Rio Paracauari, Soure, Ilha do Marajó, Estado do Pará. Dissertação de Mestrado, Universidade Federal do Pará, 95p.

Bemerguy R. 1997. Morfotectônica e Evolução Paleogeográfica da Região da Calha do Rio Amazonas. Tese de Doutoramento, Universidade Federal do Pará, 200p.

Bemerguy R.L., Costa J.B.S., Hasui Y., Borges M.S., Soares Jr.A.V. 2002. Structural geomorphology of the Brazilian Amazon region. In: Klein E.L., Vasquez M.L., RosaCosta L.T. (eds.) Contribuições à Geologia da Amazô- nia. SBG, Núcleo Norte, p. 245-257.

Costa J.B.S., Borges M.S., Bemerguy R.L., Fernandes J.M.G., Costa Jr., Costa M.L. 1993. A evolução cenozóica da região de Salinópolis, nordeste do Estado do Pará. Geociências, 12:373-396.

Costa J.B.S., Hasui Y., Borges M.S., Bemerguy R.L. 1995. Arcabouço tectônico mesozóico-cenozóico da região da calha do Amazonas. Geociências, 14:77-83.

Costa J.B.S., Bermeguy R.L., Hasui Y., Borges M.S., Ferreira Jr. C.R.P., Bezerra P.E.L., Costa M.L., Fernandes J.M.G. 1996. Neotectônica da região amazônica-aspectos tectônicos, geomorfológicos e deposicionais. Geonomos, 4:23-44.

Costa J.B.S. \& Hasui Y. 1997. Evolução geológica da Amazônia. In: Costa M.L. \& Angélica R.S. (eds.) Contribuições à Geologia da Amazônia. SBG, Núcleo Norte, p.15-19.

Costa J.B.S.C., Bemerguy R.L., Hasui Y., Borges M.S. 2001. Tectonics and paleogeography along the Amazon River. $J$ South Am Earth Sci, 14:335-347.

Costa M.L., Moraes E.L., Behling H., Melo J.C.V., Siqueira N.V.M., Kern D.C. 1997. Os sedimentos de fundo da Baía de Caxiuanã. In: Lisboa P.L.B. (ed.) Caxiuana: Populações Tradicionais, Meio Físico e Diversidade Bioló- 
gica. Museu Paraense Emílio Goeldi, p. 121-137.

Costa M.L., Kern D.C., Behling H., Borges M. 2002. Geologia. In: Lisboa P.L.B. (ed.) Caxiuanã: Populações Tradicionais, Meio Físico e Diversidade Biológica. Museu Paraense Emílio Goeldi, p.179-206.

Curkendall D., Fielding, E.J., Cheng T., Pohl J.M.A. 2003. Computational-Grid Based System for Continental Drainage Network Extraction Using SRTM Digital Elevation Models. Proceedings of the International Conference on Parallel Processing Workshops (ICPPW03), p. 181.

Deffontaines B. \& Chorowicz J. 1991. Principles of drainage basin analysis from multisource data: Application to the structural analysis of the Zaire Basin. Tectonophysics, 194:237-263.

Doornkamp J.C. 1986. Geomorphological approaches to the study of neotectonics. J. Geol Soc, 143:335-42.

Galvão M.V.G. 1991. Evolução Termodinâmica da Bacia do Marajó. Dissertação de Mestrado, Universidade Ouro Preto, 193p.

Jenson S.K. \& Domingue J.O. 1988. Extracting topographic structure from digital elevation data for geographic information system analysis. Photog Eng Rem Sens, 54:1593-1600.

Jordan G., Meijninger B.M. L., Hinsbergen D.J.J., Meulenkamp J.E., Dijk P.M. 2005. Extraction of morphotectonic features from DEMs: Development and applications for study areas in Hungary and NW Greece. Int J App. Earth Obs Geoinf, 7:163-182.

Ibanez D.M. 2006. Integração de dados de sensoriamento remoto (SRTM e RADARSAT-1), geologia, gravimentria e magnetometria para estudo morfoestrutural da área do Rio Uatumã, Bacia do Amazonas. Dissertação de Mestrado, Instituto Nacional de Pesquisas Espaciais, 161p.

Keller E. \& Pinter N. 1996. Active tectonics: earth-quake, uplift and landscape. New Jersey, Prentice Hall, 338p.

Martins A.K.E., Silva E., Schaefer C.E.G.R., Soares V. 2005. Mapeamento de unidades geomofológicas na Fazenda Lago Verde, planície do Araguaia, município de Lagoa da Confusão, estado do Tocantins. In: Simp Bras Sens Rem, 12, Anais, p.1831.

Martz L.W. \& Garbrecht J. 1992. Numerical definition of drainage networks and subcatchment areas from digital elevation models. Comp \&. Geosc, 18:747-761.

O'Leary D.W., Friedman D.D., Pohn H.A. 1976. Lineament, linear, lineation: some proposed new standards for old terms. Bull Geol Soc Am, 87:1207-1248.

Paradella W.R., Santos A.R., Veneziani P., Morais M.C. 2000. Synthetic Aperture RADAR for Geological Applications in the Moist Tropics: Experiences from the Brazilian Amazon Region. Rev Bras Geoc, 30:538-542.

Paradella W.R., Santos A.R., Veneziani P., Sant'Anna M.V., Morais M.C. 2000. Geological Investigation Using RADARSAT-1 Images in the Tropical Rain Forest Environment of Brazil. Can J Rem Sens, 26:81-89.

Paradella W.R., Cecarelli I.C.F., Oliveira C.G., Luiz S., Morais M.C., Cottini C.P. 2001. A geração de modelos digitais de elevação pela estereoscopia de radar: Conhecimento atual e resultados com imagens RADARSAT-1 na Amazônia. In: Simp Bras Sens Rem, 10, Anais, p. 1333.
Porsani M.J. 1981. Paleocanais, uma opção para prospecção de água subterrânea na Ilha de Marajó. Dissertação de Mestrado, Universidade Federal do Pará, 109p.

Potter P.E. 1997. The Mesozoic and Cenozoic paleodrainage of South America: a natural history. J. South Am. Earth Sci., 10:331-334.

RADAM. 1974. Geologia, geomorfologia, pedologia, vegetação e uso potencial da terra. Folha SA.22-Belém. Série levantamento de recursos naturais do Projeto RADAMBRASIL. Rio de Janeiro, DNPM, Mapa Temático, escala 1:1.000.000.

Rossetti D.F. \& Valeriano M.M. 2007. Evolution of the lowest Amazon Basin modeled from the integration of geological and SRTM topographic data. Catena, 70:253-265.

Rossetti D.F., Valeriano M.M., Thallês M. 2007. An abandoned estuary within Marajó Island: implications for late Quaternary paleogeography of northern Brazil. Est. and Coasts, 30:813-826.

Rossetti D.F., Góes A.M., Valeriano M.M., Miranda A.C.C. 2008a. Quaternary tectonics in a passive margin: Marajó Island, northern Brazil. J Quat Sc, 23:121-135.

Rossetti D.F., Valeriano M.M., Góes A.M., Thales M. 2008b. Paleodrainage in Marajó Island (northern Brazil) and its relation to Holocene relative sea-level. The Holocene, 18:923-934.

Rozo J.M.G., Nogueira A.C.R., Carvalho A.S. 2005. Análise multitemporal do sistema fluvial do Amazonas entre a ilha do Careiro e a foz do rio Madeira. In: Simp Bras Sens Rem, 12, Anais, p. 1875.

Silva C.L. 2005. Análise da tectônica Cenozóica da região de Manaus e adjacências. Tese de Doutoramento, Universidade Federal do Amazonas, 282p.

Silva C.L., Morales N., Crosta A.P., Costa S.S., JimenezRueda J.R. 2007 Analysis of tectonic-controlled fluvial morphology and sedimentary processes of the western Amazon Basin: an approach using satellite images and digital elevation model. An Acad Bras Ciênc, 79:693711.

Souza-Filho P.W.M. 2000. Tectonic control on the coastal zone geomorphology of the northeastern Pará State. Rev Bras Geoc, 30:523-526.

Souza Filho P.W.M. \& El Robrini M. 2000. Coastal Zone Geomorphology of the Bragança Area, Northeast of Amazon Region, Brazil. Rev Bras Geoc, 30:518-522.

Souza-Filho P.W.M. \& Paradella W.M. 2003. Use of Synthetic Aperture Radar Images for Recognition of Coastal Geomorphological Features, Land-Use Assessment and Shoreline Changes in Bragança Coast, Pará, Northern Brazil. An. Acad. Bras. Ciênc., 75:341-356.

Szatmari P., Fraçolin J.B.L., Zanotto O., Wolff S. 1987. Evolução tectônica da margem equatorial brasileira. Rev Bras Geoc, 17:180-188.

Villegas J.M.C. 1994. Geologia Estrutural da Bacia do Marajó. Dissertação de Mestrado, Universidade Federal do Pará, 119p.

Manuscrito ID 10511 Submetido em 03 de julho de 2008 Aceito em 11 de fevereiro de 2009 